\title{
LÍNGUA E ESPAÇO EM CONTEXTOS DE DIVERSIDADE LINGUÍSTICA ${ }^{1}$ DOI: $10.48075 /$ RI.V22I2.26250
}

Anderson Lucas da Silva Macedo² Mônica Maria Guimarães Savedra ${ }^{3}$

RESUMO: O presente trabalho propõe uma reflexão sobre a estreita relação entre língua, espaço e diversidade linguística, a partir de estudos que têm em conta a temática do plurilinguismo. $\mathrm{O}$ artigo também considera a dialetologia tradicional do século XIX, fortalecida pelos estudos da sociolinguística desde a segunda metade do século $X X$, para alcançar a discussão proposta. $O$ espaço aqui é compreendido através de três perspectivas: espaço linguístico geográfico (ou físico), espaço linguístico social e espaço linguístico político. Auer e Schmidt (2010) é a obra teórica principal na qual este estudo se debruça. A delimitação do campo de estudo em Timor-Leste, justifica-se pela sua natural diversidade linguística em movimento e também pelas recentes ações políticas, tais como a legitimação de sua independência e promulgação da sua Constituição no início do desse século (2002), que elegeu somente duas línguas como oficiais em um país reconhecidamente plurilíngue tanto individual como socialmente, ou seja, indivíduos que usam mais de uma língua em espaços onde mais de uma língua é utilizada ${ }^{4}$.

Palavras-chave: Língua portuguesa; Timor-Leste; política linguística

\section{LANGUAGE AND SPACE IN LINGUISTIC DIVERSITY CONTEXT}

ABSTRAC: This work proposes a reflection on the relationship between language, space and linguistic diversity, based on plurilingualism studies. The traditional dialectology of the 19th century, strengthened by the studies of sociolinguistics since the second half of the 20th century, is used in order achieve the proposed discussion. In this paper, space is viewed from three perspectives: geographic (or physical) linguistic space, social linguistic space and political linguistic space. Auer and Schmidt (2010) is the main theoretical work on which this study focuses. The delimitation of the field of study in East Timor is justified by its natural linguistic diversity in movement and also by recent political actions, such as the legitimization of its independence and the promulgation of the Constitution at the beginning of that century (2002), which elected only two official languages in a country recognized as individual and socially plurilingual, in other words, individuals who use more than one language in spaces where more than one language is spoken.

\footnotetext{
${ }^{1}$ Essa publicação foi feita com apoio da Coordenação de Aperfeiçoamento de Pessoal de Nível Superior - Brasil (CAPES) - Código de Financiamento 001.

${ }^{2}$ Doutorando em Estudos de Linguagem, UFF, Niterói, Rio de Janeiro. Pesquisador bolsista do Cnpq. e-mail: andersonlucasm@gmail.com

${ }^{3}$ Professora Associada da Universidade Federal Fluminense, Niterói, RJ. Pesquisadora bolsista do Cnpq. e-mail: msavedra@id.uff.br

${ }^{4}$ Optamos por utilizar a terminologia usada em Savedra e Perez (2017), onde os autores denominam plurilinguismo individual a situação em que indivíduos falam mais de uma língua e plurilinguismo social a situação de coexistência de mais de uma língua em situações de interação nos diferentes ambientes de contato.
} 
Key Words: Language; Space; East Timor.

\section{INTRODUÇÃO}

O presente artigo tem como objetivo principal propor reflexões sobre a relação entre língua, tempo e espaço linguístico tomando a realidade linguística de Timor-Leste como exemplo empírico. O texto está organizado em duas seções. Na primeira apresentamos as discussões teóricas dos estudos que contemplam as relações espaço nos estudos linguísticos, para então na parte seguinte nos determos na descrição de nosso campo de estudo, ou seja, a diversidade linguística em Timor-Leste.

O espaço linguístico será apresentado por meio de três ângulos. O primeiro ângulo é o geográfico (ou físico) e faz menção aos primeiros estudos de dialetologia ${ }^{5}$ e sua trajetória até os dias de hoje. O segundo observa o espaço em sua perspectiva social, abordando, inclusive, teorias da sociologia sobre a relação entre sujeitos e espaço e servirá de base teórica e metodológica para o estudo de campo, que se caracteriza como uma pesquisa qualitativa de base etnográfica. Finalmente, o espaço linguístico político será mencionado trazendo a discussão de como o conceito tradicional de Estado-nação se relacionou com o uso e cuidado das línguas.

A segunda seção mostrará, de modo breve, a realidade linguística timorense e como pode ser vista a partir da perspectiva do espaço, tendo em consideração os três ângulos mencionados acima. O universo plurilíngue do Timor será apresentado dentro de uma perspectiva histórica (tempo) onde são identificamos momentos importantes de sua diversidade linguística.

\section{OS ESPAÇOS GEOGRÁFICO, SOCIAL E POLÍTICO}

\section{ESPAÇO LINGUÍSTICO GEOGRÁFICO}

A relação entre os estudos linguísticos e o espaço geográfico sempre foi objeto de estudo das ciências da linguagem, em especial aqueles que se dedicam ao contato sociolinguístico, já que uma das formas dos falantes se organizam é em espaços geográficos.

\footnotetext{
${ }^{5} \mathrm{O}$ conceito de dialetologia usado neste texto é o mostrado em Cardoso (2010, p.15), "um ramo dos estudos linguísticos que tem por tarefa identificar, descrever e situar os diferentes usos em que uma língua se diversifica, conforme a sua distribuição espacial, sociocultural e cronológica.”.
} 
Dossiê: Atitudes Linguísticas e Políticas Linguísticas: abordagens interdisciplinares

Várias investigações sobre a relação língua e espaço se apoiaram nas bases teóricometodológicas da geografia para modelarem suas pesquisas. Em estudos atuais na área da Sociolinguística, o espaço geográfico tem sido abordado em diferentes tópicos específicos, tais como variações e mudanças linguísticas em movimento, 'place identity', 'linguistic landscape' e 'linguistic soundscape' (JONHSTONE, 2010)

Ao comentar a relação entre língua e espaço físico, faz-se necessário abordar a dialetologia e sua importância. Entende-se por dialetologia o estudo sistemático e organizado dos dialetos (CRYSTAL, 2008). Esse estudo, que também pode ser chamado de geografia linguística, começou no fim do século XIX. Pesquisadores de campo faziam um trabalho com entrevistas a falantes locais e assim mapeavam as áreas dialetais, identificando os limites físicos de mudanças lexical e fonológica. Os resultados obtidos (as variações regionais, seja vocabular seja fônica) eram cartografados provendo exemplo de junção de informações linguísticas e espaço geográfico. Se, em alguma determinada região, fosse encontrado um certo número de itens distintivos, era possível afirmar que havia um dialeto naquela área. Saber onde os falantes estão e de onde vieram sempre se revelou um interessante e pertinente aspecto para os estudiosos. Além disso, os pesquisadores conseguiam delimitar geograficamente onde terminava uma variedade linguística e começava outro através das linhas de isoglossas. Com base nisso, pode-se citar um trecho do texto de Barbiers (2010):

\begin{abstract}
O alvo da dialetologia tradicional é descrever e comparar sistemas individuais de dialetos e mostrar a distribuição geográfica de suas propriedades linguísticas. O foco está na variação dos domínios lexical, fonético e morfológico. Mapas geográficos são o principal resultado dessa pesquisa. Esses mapas mostram áreas dialetais e (um grupo de) isoglossas, as fronteiras entre diferentes áreas dialetais definidas por uma ou mais variáveis linguísticas. (BARBIERS, 2010, p. 126, tradução nossa) ${ }^{6}$
\end{abstract}

No tocante aos atlas linguísticos, Cardoso (2010) traz a seguinte classificação para essas obras: podem ser regionais, nacionais, de grupos linguísticos e continentais. A autora menciona a importância do 'Atlas Linguistique de la France' (1909), de Guillierón, como um

\footnotetext{
${ }^{6}$ The goal of traditional dialectology is to describe and compare individual dialect systems and to show the geographic distribution of their linguistic properties. The focus is on variation in the lexical, phonetic and morphological domain. Geographic maps are the primary output of this research. These maps show dialect areas and (bundles of) isoglosses, the borders between different dialect areas defined by one or more linguistic variables.
} 
Dossiê: Atitudes Linguísticas e Políticas Linguísticas: abordagens interdisciplinares

dos inauguradores dos trabalhos de cunho nacional. Essa obra foi capaz de cobrir todo o território francês e traz um importante panorama linguístico do território dessa nação europeia. O autor criou um formulário com 1900 questões e buscou investigar aspectos morfológicos, sintáticos e lexicais da língua francesa. Sua pesquisa inclui não apenas a

França, mas também outras regiões francófonas na Europa, como a Suíça.

O mapeamento feito na dialetologia foi bastante usado pela Linguística do século XIX e é definitivamente a primeira aproximação dessa ciência com os conceitos de espaço geográfico e/ou físico (HIGGINS, 2017).

Uma das relevâncias em se analisar o espaço geográfico é que assim é possível evidenciar a variedade que a língua assume de uma região para outra. Tal variedade se manifesta porque a língua reflete a diversidade cultural, o contato com outras línguas (se for o caso) e, também, a característica demográfica da região (CARDOSO, 2010).

Jonhstone (2010) aborda como a ciência da linguagem tem lidado com o tema do espaço desde o século XIX. A autora mostra que a linguística e a geografia estiveram nas mesmas correntes políticas e intelectuais nos últimos dois séculos. A expressão usada pelos geógrafos 'espaço geográfico' pareceu adequada para tentar ajudar a compreender distribuição de determinadas formas linguísticas no tempo e no espaço.

Os estudos sociolinguísticos quantitativos de Labov, nos anos 1960, atraem a atenção de vários pesquisadores, que deixam a dialetologia tradicional, pelo menos parte dela, e passam o olhar para as cidades através de suas características demográficas como, por exemplo, etnia, idade, gênero e outros padrões que pudessem ser, de algum modo, relacionados à variação e à mudança linguística. Isso se deve ao fato de a sociolinguística laboviana adotar uma metodologia capaz de relacionar fatores linguísticos e sociais visando compreender e explicar o fenômeno da mudança linguística

Entre 1960 e 1970 uma descrença em métodos social-científicos quantitativos ocorre, bem como em parte da teoria social que havia sido aplicada anteriormente. Modelos teóricos marxistas e neomarxistas passam a ser explorados. A geografia humana ${ }^{7}$, que nessa fase aliase aos estudos das humanidades, passa a observar o lugar através da descrição das interações humanas com o ambiente e, também, analisa as políticas das representações do espaço. A

\footnotetext{
${ }^{7}$ Essa nova vertente da geografia se originou como uma reação à maneira considerada antiga de se fazer a geografia. Esse movimento acompanhou o marxismo e o feminismo da época.
} 
geografia humana trata dos lugares sempre através de uma experiência subjetiva, por exemplo, a experiência de uma casa não é dada pela descrição objetivo do prédio em si ou coordenadas geográficas, mas como um conjunto de emoções ligadas à casa e sensações como o cheiro, som, imagens. A sociolinguística da época segue caminhos bastante parecidos e estuda a maneira como espaço físico modela espaço social e vice-versa e, também, como a experiência de espaço pode modelar o comportamento linguístico dos falantes.

No começo dos anos 80 do século passado, a Sociolinguística e a Dialetologia passam a considerar a relação entre ambientes físicos e ambientes sociais. A teoria 'social network', da sociologia, passa a ser usada também nas ciências da linguagem. Tal teoria observa como a complexidade e diversidade das relações sociais dos falantes, isto é, a quantidade de indivíduos e a maneira como um falante interage com as pessoas. Essa teoria prevê que pessoas com um número elevado de contatos (no inglês o termo usado é 'neighbors', vizinhos, e se refere às pessoas com que se trabalha junto, pratica atividades, compartilham atos religiosos etc.) e poucas pessoas de outras regiões (do inglês, 'outsiders') tendem a preservar formas linguísticas usadas pelos seus contatos, já que estão menos expostas a formas inovadoras. Isso ajuda a entender a relação entre classes sociais e mudanças linguísticas, uma vez que alguns grupos pertencem a redes que naturalmente inibem a entrada de novas formas linguísticas.

A relação entre língua e espaço pode também ser vista pela perspectiva de como o espaço se torna tão importante quanto os 'lugares humanos' (do inglês, 'human places'). Estuda-se a relação entre o lugar físico e o lugar com um 'significado'. Para que um lugar se torne 'humano' é necessário haver fala, discurso (do inglês, 'talk') e os significados dos lugares irão modelar como as pessoas falam.

Em se tratando particularmente do Brasil, as primeiras preocupações com a geografia linguística surgem nos meados do século XX. Os estudiosos da área se interessaram pela confecção de um atlas linguístico nacional e, assim, a dialetologia é estabelecida aqui (CARDOSO, 2010). Já na década de 1960, com o advento da sociolinguística e sua consequente aceitação nas pesquisas brasileiras, a dialetologia passa ser menos usada. 0 interesse dos pesquisadores se centraliza na relação língua e sociedade e não mais língua e geografia. Entretanto, nos últimos anos parece ter havido um novo interesse pelos estudos língua e espaço geográfico (não só na Europa, mas no Brasil também). Isto se reflete, no Brasil, na 
elaboração de atlas linguísticos e várias teses de doutorado tratando desse tema. Nas palavras de Mota e Cardoso (2000):

As observações sobre o léxico constituem-se na primeira manifestação mais amplamente documentada de reconhecimento da diversidade linguística em nosso país, e, no caso inicial, atestada entre o falar de Portugal e o falar brasileiro. Tal linha de investigação prossegue por todo esse século. São glossários, léxicos, dicionários e vocabulários que vão tratar de assinalar as peculiaridades de áreas, caracterizando-as e distinguindo-as, e, ao mesmo tempo configuram do a diversidade na considerada unidade do português brasileiro. (p. 42)

\section{ESPAÇO LINGUÍSTICO SOCIAL}

O espaço social é, de acordo com a Sociologia, onde se encontram os agentes sociais; é o espaço multidimensional no qual as relações sociais acontecem, sempre por meio da interação entre os atores sociais. Nesses espaços sociais, tais atores interagem por meio da linguagem ${ }^{8}$. Lugares como igreja, mercado e universidade podem ser tidos como exemplos. No espaço social, os agentes constroem suas identidades e, assim, as diferenças entre as posições sociais são compreendidas.

O conceito apresentado acima foi trazido por Pierre Bourdieu, sociólogo francês, e tem sido de amplamente usado em estudos das humanidades em geral. A sociologia, nesse aspecto, contribui com a linguística de modo a enxergar mais profundamente as relações sociais. A sociologia compreende os seres humanos como indivíduos biológicos e, ao mesmo tempo, como agentes sociais. Enquanto seres biológicos, os indivíduos ocupam um local (um sítio, um lugar onde um agente ou coisa se situa; localização). Enquanto agentes sociais, os indivíduos ocupam o espaço social - espaços onde se organizam os agentes. Esses agentes são caracterizados pelos lugares em que se situam (como no caso do domicílio, por exemplo) e pela posição que ocupa no espaço (juridicamente) e também através de suas propriedades (bens). Assim os lugares e locais que os agentes ocupam mostram a sua posição no espaço social. O espaço social não é como o físico, embora o social se manifeste num espaço físico. 0 espaço que se conhece é socialmente delineado e é constituído por campos, como, por

\footnotetext{
${ }^{8}$ É importante lembrar que na sociologia a linguagem é vista como um fenômeno plenamente social. A língua é observada levando sempre em consideração seus contextos reais sociais.
} 
exemplo, o campo intelectual, o campo econômico etc. O espaço social se materializa no espaço físico através de diversos tipos de bens e serviços e dos agentes (tanto individuais como em grupos) e suas eventuais capacidades de apropriar-se desses bens e serviços.

A sociolinguística, para alcançar seus objetivos, precisa entender a língua num contexto social e cultural. A língua deve ser vista como um sistema de sinais com referência a traços socioculturais. Qualquer variedade linguística escolhida pelo falante será interpretada como um indicador para sua representatividade social e identidade (BOURDIEU 2008; MAEHLUM, 2010). A experiência vivenciada entre espaço social e espaço geográfico pode ser invocada pela relação existente entre a língua padrão falada (do inglês, 'spoken standard language') e o dialeto (língua não padrão) e o contraste entre eles. Mæhlum (2010) mostra que a separação feita entre língua padrão falada e a não padrão é originalmente geográfica, no entanto isso tem sido interpretado principalmente como uma expressão de identidade social. Por exemplo, uma marca de um determinado dialeto geralmente é ligada a uma posição social específica em vez de um indicador geográfico. A territorialidade de uma língua é entrelaçada com outros de seus aspectos, inclusive aspectos de natureza social.

Uma maneira de se observar o espaço linguístico social é saber como os falantes, dentro de uma comunidade de fala ${ }^{9}$, percebem os dialetos e idioletos e reagem a eles. Tomese como exemplo os dialetos regionais que indicam a origem de um falante - não é difícil para os falantes distinguirem os dialetos urbanos dos rurais, pois cada um apresenta suas respectivas características e complexidades. Os dialetos podem também sugerir ou indicar a classe social de um falante; algumas línguas são mais estratificadas do que outras no que tange à divisão social (idade, gênero, profissão, classe financeira entre outros).

Bourdieu (2008) salienta que o ato de fala implica uma acomodação e escolha por parte do falante de opções linguísticas e estilísticas já existentes. Ao fazer essa escolha, o sujeito se situa na estrutura dos grupos sociais, em outros termos, ele opta por onde estar socialmente. A variação linguística usada pelo falante, portanto, se relaciona com as camadas hierárquicas presentes em sua comunidade. Como é esperado em sociedades grandes e

\footnotetext{
9 Para 'comunidade de fala' usamos o conceito dado por Labov (1972). De acordo com o sociolinguista, comunidade de fala é aquela em que os falantes compartilham normas e atitudes sociais perante uma língua (ou uma variedade da língua). Isso não quer dizer que os membros de tal comunidade tenham que falar da mesma maneira, mas compartilham um conjunto de avaliações sobre a comunidade de fala. Tal comunidade é o objeto dos estudos laboviano.
} 
complexas, falantes de posições hierárquicas diferentes precisarão eventualmente interagir podendo causar tensões entre duas ou mais variantes. O sociólogo francês afirma ainda que, embora todos os falantes tenham condições biológicas iguais de construção de sentenças, por exemplo, nem todas as sentenças são suscetíveis de serem escutadas por certos sujeitos. Isso não se relaciona diretamente com gramaticalidade; locutores desprovidos de determinados recursos estilísticos podem ser excluídos de alguns 'universos sociais' e 'se veem condenados ao silêncio'. Aqui não é a capacidade natural de falar que está sendo questionada e sim a competência esperada para falar a 'língua legítima que, por depender do patrimônio social, retraduz distinções sociais na lógica propriamente simbólica dos desvios diferenciais ou, numa palavra, da distinção' (BOURDIEU, 2008, p. 42).

Ainda sobre Bourdieu e sua visão sobre a linguagem, Calvet (2002) lembra que o sociólogo chama a atenção para o fato de que não se deve observar a língua isolada da história social que a cerca:

Isso significa que, para Bourdieu, para além da simples comunicação de sentido, os discursos são signos da riqueza, signos de autoridade, eles são emitidos para ser avaliados e obedecidos, e que a estrutura social está presente no discurso. A partir disso podem-se desenvolver diferentes estratégias. Quanto mais um falante possui "capital linguístico" (capital essencialmente simbólico, razão pela qual seu poder deve ser reconhecido pelo grupo), mais livre ele é para jogar no mercado, utilizando por exemplo o que Bourdieu chama de "estratégias de condescendência" ("estamos em casa", "falamos a mesma língua"), derivadas da manipulação. (CALVET, 2002, p. 95-96)

\section{ESPAÇO LINGUÍSTICO POLÍTICO}

Sabe-se que o poder da comunicação oral e escrita ultrapassa muitas barreiras geográfico-políticas, especialmente nos dias de hoje com a presença de tanta tecnologia, especialmente ligada à internet. Ainda assim, de acordo com Gal (2010), a língua está ligada a um território geográfico mediado por práticas políticas. Existem muitas conexões que unem o conceito de língua a um território e isso se vincula com a ideia de Estado-nação com a pressuposição de haver unidade linguística. De acordo com o conceito tradicional de Estadonação, explica a autora, espera-se que os falantes possuam a virtude de competência linguística. Os Estados podem escolher qualquer sistema político que almejarem, tal escolha é geralmente veiculada por meio de uma língua padronizada (do inglês, 'standardized 
language') e com tradição literária. Além disso, existe a suposição de haver homogeneidade linguística na nação, essa suposição é característica muito importante da lidimidade do Estado. Gal (2010) afirma que a relação existente entre língua e espaços políticos é sempre mediada por sistemas culturais.

Lagares (2018) lembra que o conceito de Estado-nação é relativamente novo na História e que surgiu como um desejo burguês de uma 'comunidade imaginada'. O autor afirma ainda tal ideia é uma 'realidade social construída'. A nação abre espaço para que se crie vínculos entre pessoas trocando experiências como membros de uma mesma comunidade. Nessa comunidade é preciso estabelecer um mercado literário (livros, jornais, revistas etc) para que esses vínculos se tornassem fortes entre os cidadãos, compartilhando, desse modo, conhecimento de ordem política e referências culturais. Ainda tratando sobre essa:

Essas atividades linguísticas constituem a realidade social, tal e como entendida por todos, ao mesmo tempo em que determinavam sua própria existência. As transformações linguísticas que essas atividades promovem, no sentido da fixação de um modelo mais ou menos uniforme da língua escrita, com o desenvolvimento de características próprias de cada um dos gêneros discursivos utilizados, têm uma dimensão eminentemente política. (LAGARES, 2018, p. 51).

Na primeira subseção deste texto foram mencionados os primeiros passos da geografia linguística na produção os atlas linguísticos. Os conceitos de espaço geográfico e espaço político interagem nesse aspecto. O começo da geolinguística está, de certa forma, ligado ao entendimento do espaço político uma vez que busca entender a realidade de uma nação respeitando seus limites políticos (CARDOSO, 2010). É importante lembrar que as fronteiras utilizadas em muitos desses atlas apresentam e respeitam as fronteiras políticas - muito embora seja do conhecimento dos linguistas que os dialetos não podem ser contidos por tais barreiras. Em outros termos, os dialetos e os limites políticos nem sempre coincidem. Por isso, a criação de atlas regionais (e não apenas nacionais) se fez necessária numa tentativa de aprofundar o conhecimento dialetal de um determinado espaço. 
Krefeld (2010) explica que um dos reflexos da noção de espaço trazida pelas ideias europeias de Estado-nação é a dificuldade de incluir as novas minorias de imigrantes, isso devido a uma visão do espaço bastante rígida e naturalista. A pesquisadora ainda afirma que a desconsideração por migração e novas minorias no paradigma dialetal provavelmente vem dessa política.

Em se tratando mais especificamente da relação linguística e espaço político, Gal (2010) afirma que mapa linguístico é ainda bastante usado devido a várias instituições sociais que utilizam imagens sociolinguísticas trazidas em tais mapas. Citando Bakhtin (1981), Gal mostra que a diversidade de variedades, a proliferação de diferentes estilos, sotaque e registros estão onipresentes em todas as línguas e que essas variações são básicas a todas elas. O processo de padronização linguística é, dentro da perspectiva de Estado-nação, esperado e as instituições relacionadas ao governo agem a esse respeito. Lagares (2018) acrescenta que a padronização da língua faz com que os diversos documentos do governo bem como os seus funcionários possam se movimentar livremente dentro do espaço nacional. Algumas estratégias políticas relacionadas à padronização da língua são: a distribuição de jornais, revistas e livros escritos com a ortografia oficial, a criação de gramáticas e dicionários, currículo escolar, academia de letras, entre outras.

Diante de toda essa padronização, sugiram algumas crenças a respeito da língua padrão, como a de que esta é mais correta e sofisticada do que as outras variedades. Em outras palavras, há uma supervalorização pelo o que é padrão. Isto afeta significativamente a maneira como falantes lidam com sua própria língua. As outras formas são, portanto, vistas não simplesmente como diferentes ou típicas de determinada região geográfica, mas como inferiores ou menos sofisticadas. Muitas escolas, mesmo que indiretamente, inserem esse modo de pensar em seus alunos e quando esses não aprendem a língua padrão conforme o esperado pela sociedade, são reprovados. Muitas vezes o sistema escolar lida com o ensino da variedade padrão de maneira tal a não reconhecer o papel das outras variedades.

Digno de nota é o fato de que a padronização não ocorre por si só, naturalmente, é necessário haver quem comece tal processo. No Brasil, um grande debate a respeito do preconceito linguístico foi levantado anos atrás trazendo esclarecimento, especialmente entre os estudantes de Letras, com destaque para o trabalho de Marcos Bagno. Bagno (2007) 
Dossiê: Atitudes Linguísticas e Políticas Linguísticas: abordagens interdisciplinares

defende que o preconceito linguístico é questão prioritariamente política, posto que, na verdade, denota a rejeição às variedades linguísticas de menor prestígio.

É muito claro que nem todos Estados-nações têm o mesmo processo e tempo de padronização; isso varia de acordo com a rigidez do sistema pedagógico e sua eficácia em ser aceita pelo país todo.

Uma outra consequência do processo de padronização que pode ser assinalada é expectativa criada de que a forma padrão (ou formas padrões) seriam igualmente distribuídas pelo território físico da nação; essa expectativa além de não ser alcançada, cria outras heterogeneidades na língua e reformula a relação entre as variedades existentes expondo-as à observância.

Ainda discorrendo sobre o espaço linguístico político, pode-se destacar o esforço brasileiro no reconhecimento das línguas ${ }^{10}$ e variedades linguísticas, verdadeiro patrimônio cultural do Brasil. Em dezembro de 2010 foi instituído o Inventário Nacional da Diversidade Linguística (INDL) que é um órgão oficial com o objetivo de identificar, documentar e reconhecer as línguas faladas no Brasil. Além disso, o Inventário fomenta a produção de conhecimento sobre as línguas do Brasil e auxilia na defesa e garantia dos direitos linguísticos.

Algumas línguas já se tornaram cooficiais em alguns municípios (8 indígenas e 4 de imigração). Por exemplo, no município de São Gabriel da Cachoeira (AM) o tukano, o baniwa e o nheengatu tornam-se em 2002 línguas cooficiais (https://www.camara.leg.br/noticias). Um outro exemplo é o da língua pomerana ${ }^{11}$ que foi cooficializada em oito municípios do país, sendo que em seis somente no Estado do Espírito Santo (Pancas, Santa Maria de Jetibá, Domingos Martins, Laranja da Terra, Vila Pavão e Itarana), onde estima-se que haja cerca de 150 mil falantes desta variedade. Como já dito, o espaço político das cooficializações vem fortalecer questões identitárias das comunidades em situação minoritária, como pode ser observado no texto do decreto de 26 de junho de 2009 que cooficializa o Pomerano em Santa Maria de Jetibá ${ }^{12}$.

\footnotetext{
${ }^{10}$ O INDL categoriza as línguas em: língua de imigração, língua indígena, língua afro-brasileira, língua de sinais e língua crioula.

${ }^{11}$ A língua germânica falada em alguns municípios do Espírito Santo, Santa Catarina, Rio Grande do Sul.

12 https://leismunicipais.com.br/a/es/s/santa-maria-de-jetiba/lei-ordinaria/2009/114/1136/lei-ordinarian1136-2009-dispoe-sobre-a-co-oficializacao-da-lingua-pomerana-no-municipio-de-santa-mariade-jetiba-estadodo-espirito-santo
} 
A cooficialização tornou institucional o uso da língua que já era utilizada desde a chegada dos pomeranos. A cooficialização não somente institucionalizou a grande importância que a língua pomerana tem para a região, comunidade e identidade do povo, mas também vem aprofundar os laços identitários do povo com sua língua e cultura. (SAVEDRA; MAZELLI-RODRIGUES, 2017 p. 16).

\section{TIMOR-LESTE}

Timor-Leste é parte de uma ilha dentro do imenso arquipélago indonésio (17 mil ilhas, aproximadamente). Possui posição geográfica privilegiada: encontra-se no fim da Ásia e muito próximo à Oceania. Faz fronteira unicamente com a Indonésia; possui cerca de 1.200.000 habitantes (metade da população tem menos de 20 anos) e aproximadamente 20 línguas nativas (de origem austronésia e papua). Díli é a capital nacional e se encontra no lado norte do país.

Figura 1: Mapa de Timor-Leste

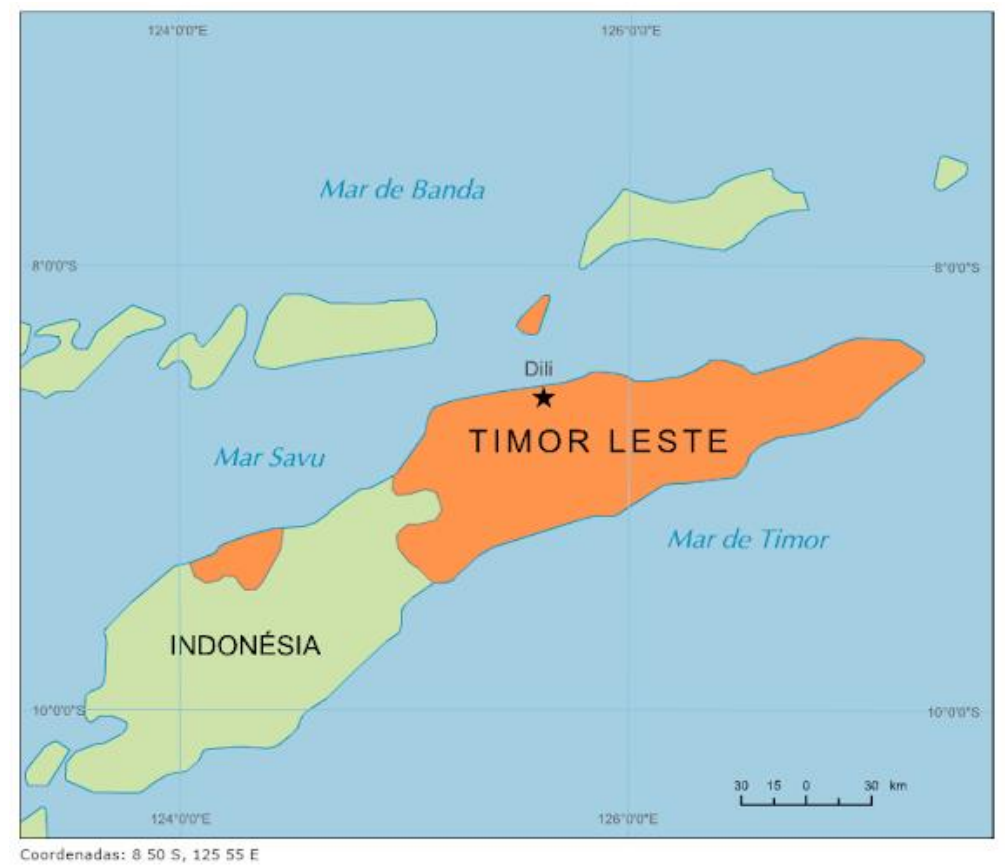

Fonte: https://suburbanodigital.blogspot.com/2015/04/mapa-de-timor-leste.html 


\section{Dossiê: Atitudes Linguísticas e Políticas Linguísticas: abordagens interdisciplinares}

Timor-Leste, uma das nações mais novas do mundo, sofreu terrível invasão ${ }^{13}$ pela Indonésia que durou 24 anos (1975-1999) resultando inúmeras execuções extrajudiciais, assassinato e também tortura. Além disso, há relatos de trabalho escravo e acredita-se que cerca de 300 mil timorenses foram mortos lutando pela independência. Importante de ser mencionado é o fato de os invasores terem proibido o uso da língua portuguesa e forçado a substituição desta língua pelo bahasa indonésio (a língua oficial da Indonésia, variante do Malaio). Em 1999, por meio da atuação da ONU, os batalhões indonésios são retirados de Timor-Leste e, finalmente, em 20 de maio de 2002 é reconhecido como um estado democrático e independente.

Hoje a nação timorense enfrenta os diversos desafios e dificuldades de um país que começou a se organizar, muito embora haja uma considerável vitória no combate à pobreza nos últimos anos. Durante os quatro séculos sob o governo português, Timor-Leste não vivenciou grande desenvolvimento econômico. Logo após, sofreu os 24 anos de invasão indonésia e também não conheceu grandes avanços, embora houvesse investimento em educação e uma certa infraestrutura.

Apesar do quadro mostrado, a composição da Constituição da República Democrática de Timor-Leste traz importantes informações para os estudos linguísticos. O texto oficial do documento elenca as duas línguas escolhidas como oficiais, o tétum e o português, como pode ser observado a seguir:

\section{Artigo 13. (Línguas oficiais e línguas nacionais)}

1. O tétum e o português são as línguas oficiais da República Democrática de Timor Leste.

2. O tétum e as outras línguas nacionais são valorizadas e desenvolvidas pelo Estado. (CONSTITUIÇÃO..., 2010, p.11-12)

Digno de nota é fato de que não houve nenhum voto contra a oficialização do português pela Assembleia no dia da eleição das línguas oficiais. Dessa forma, as políticas linguísticas da nação já têm uma orientação e um alvo, mesmo que ainda em situação bastante

${ }^{13}$ Os indonésios adentraram o território timorense em 7 de dezembro de 1975 com um discurso anticolonialista. Isso ocorreu logo após o fim da colonização portuguesa em Timor-Leste em 24 de abril em 1974. A Indonésia foi apoiada pelos Estados Unidos e a Austrália (os quais proveram armamento militar para ajudar na invasão e ocupação) que temiam uma possível conversão timorense aos ideais comunistas. A resistência timorense foi facilmente vencida pelas tropas da Indonésia e, assim, o Timor foi declarado como uma das províncias indonésias. 
embrionária (MACEDO, 2019). Outro dado bastante relevante para a linguística no texto constitucional de Timor-Leste é a menção de duas línguas de trabalho: o inglês e o indonésio.

\section{Artigo 159.o (Línguas de trabalho)}

A língua indonésia e a inglesa são línguas de trabalho em uso na administração pública a par das línguas oficiais, enquanto tal se mostrar necessário. (CONSTITUIÇÃO..., 2010, p.45).

Como já apresentado, o Timor Leste é um país com território pequeno (uma área de aproximadamente $15.000 \mathrm{~km}^{2}$ ), no entanto é marcado por uma enorme diversidade linguística. Os linguistas não concordam quanto ao número exato de línguas ${ }^{14}$ faladas; Albuquerque (2010), por exemplo, afirma que há 16 línguas faladas em Timor-Leste. As línguas nativas timorenses pertencem a dois troncos distintos: austronésia ${ }^{15}$, o que inclui o tétum praça, língua franca e oficial, e papuásica ${ }^{16}$, que inclui o makasae, outra língua muito falada na nação.

Apresentadas as principais características da nação timorense, começaremos a olhar o espaço linguístico respeito a proposta indicada na primeira seção do artigo: espaço geográfico, social e político.

\section{O ESPAÇO LINGUÍSTICO GEOGRÁFICO EM TIMOR-LESTE}

Algumas pesquisas linguísticas feitas sobre o Timor-Leste enfocando os aspectos geográficos já foram realizadas. Citamos o trabalho de Catharina Williams-van Klinken, linguista holandesa, atuante no 'Language Centre Coordinator for Dili Institute of Technology' (http://www.tetundit.tl). A autora publicou diversos textos com ênfase nas línguas timorenses e sua cultura, como o notável 'Tetun Language Course', um manual que ensina lições básicas da língua tétum a partir da língua inglesa. Este material está disponível gratuitamente no

\footnotetext{
${ }^{14}$ Visando enaltecer e respeitar as outras línguas timorenses, apresentamos os nomes delas: ataurense, baiqueno, becais, búnaque, cauaimina, fataluco, galóli, habo, idalaca, lovaia, macalero, macassai, mambai, quémaque e tocodede.

${ }^{15}$ Entende-se por língua austronésia os falares distribuídos no sudeste asiático (na região do Pacífico): a maioria das línguas faladas no arquipélago indonésio, todas as ilhas das Filipinas e Madagascar e o grupo de ilhas do Sul do Pacífico (menos a Austrália e Nova Guiné).

${ }^{16}$ Línguas da região de Papua Nova Guiné.
} 
seguinte

endereço

eletrônico:

http://www.tetundit.tl/Publications.html\#Tetun dictionaries and glossaries

Além disso, houve um censo em Timor-Leste em 2010, organizado pelo governo nacional. Dessa pesquisa houve o levantamento de dados linguísticos (como o agrupamento das línguas faladas) que foram traduzidos em forma de mapa, como pode ser visto abaixo:

Figura 2: Mapa linguístico de Timor-Leste

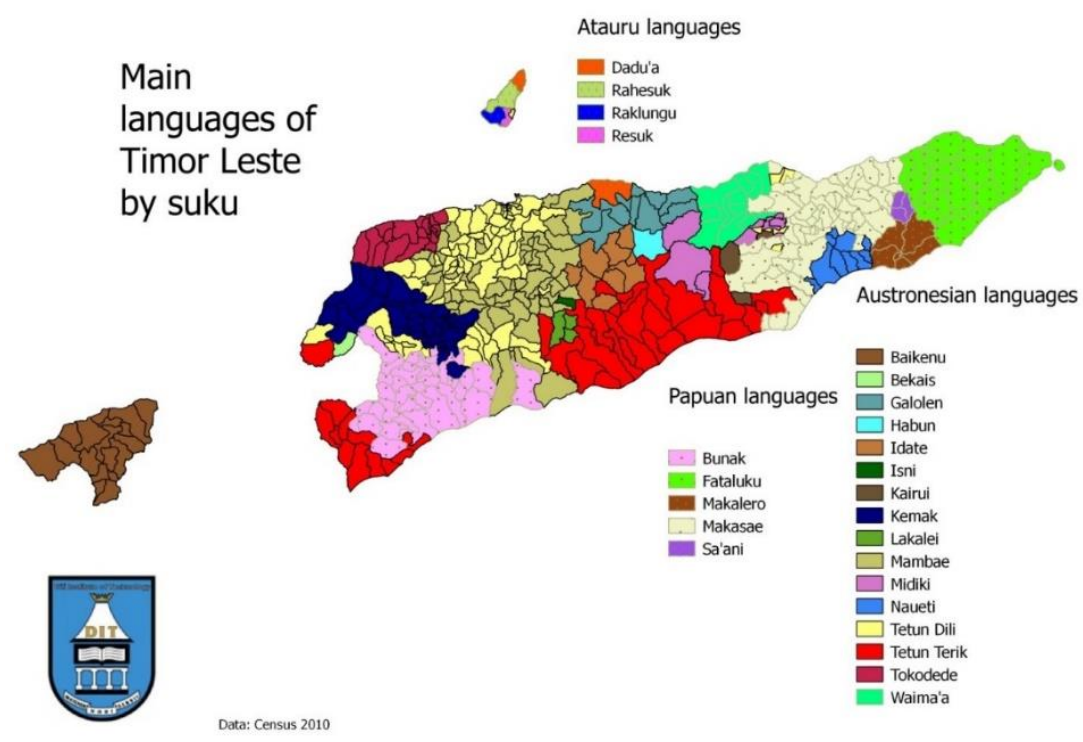

Fonte: http://www.tetundit.tl/Publications/Timor-Leste\%20languages\%202010.pdf

Conforme pode ser observado, o mapa informa, em ordem alfabética, quais são as línguas timorenses e onde se encontram geograficamente. Williams-van Klinken (2015) mostra que há outras línguas que não foram incluídas no mapa proposto porque os números de seus falantes é muito baixo ou porque as limites geográficos não são claros, como é o caso da língua 'Iolein', que é falada por cerca de 1130 pessoas e 'makuva' a qual 56 pessoas afirmaram usá-la.

Além do mapa mostrado acima, foram confeccionados diversos outros (também na ocasião do censo 2010) exibindo a porcentagem de falantes de cada língua. Por questão de 
espaço, serão apresentados apenas dois; o primeiro do tétum praça (também chamado tétum dili), por ser a língua mais falada e ser uma das línguas oficiais, e o tétum terik ${ }^{17}$ :

Figura 3: Concentração de falantes de Tétum Praça

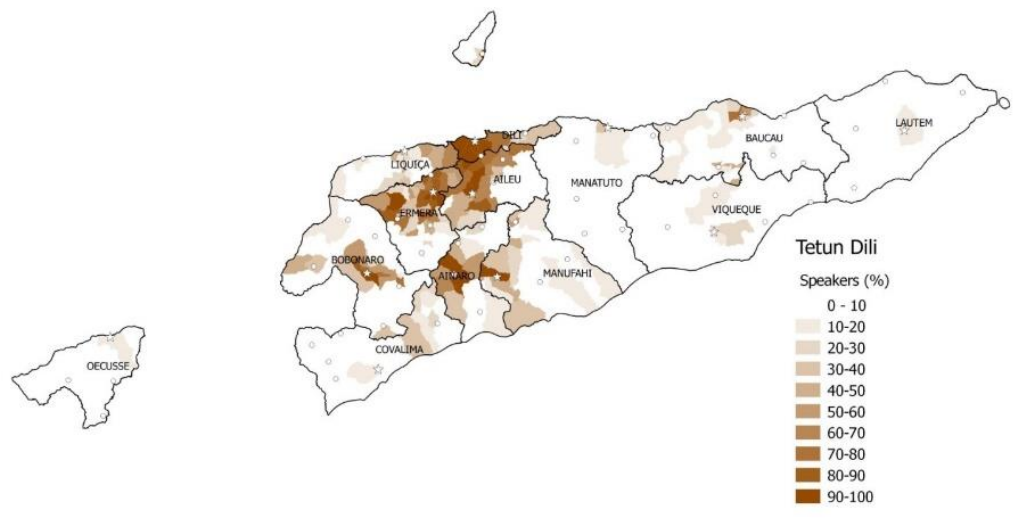

Fonte: http://www.tetundit.tl/Publications/Timor-Leste\%20languages\%202010.pdf

Figura 4: Concentração de falantes de Tétum Terik
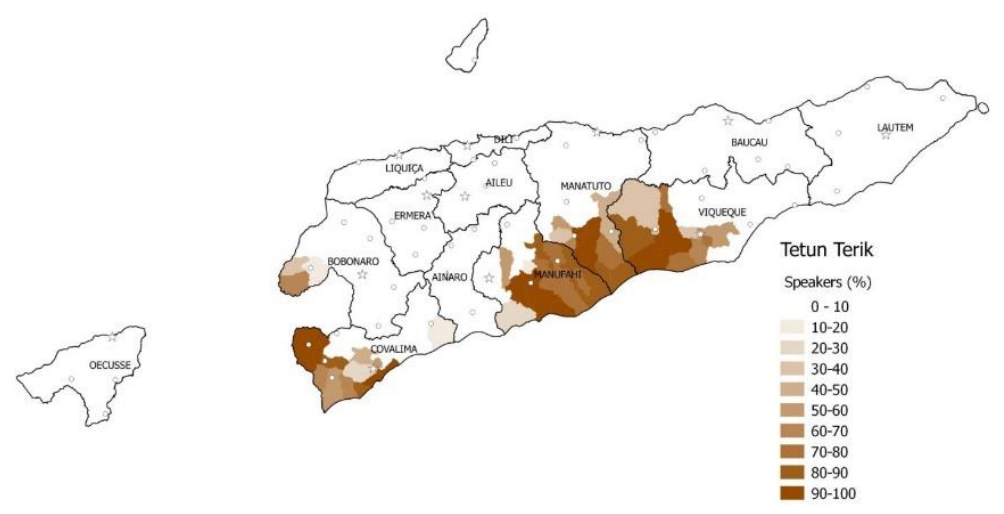

Fonte: http://www.tetundit.tl/Publications/Timor-Leste\%20languages\%202010.pdf

\section{O ESPAÇO LINGUÍSTICO SOCIAL EM TIMOR-LESTE}

O espaço linguístico social em Timor-Leste, conforme já mencionado, é composto por agentes que falam diversas línguas, já que este país é plurilíngue. O fenômeno do contato

\footnotetext{
${ }^{17}$ Em Timor-Leste, há mais de um tipo de língua tétum. O tétum praça (ou 'prasa', como escrito na própria língua) é a oficial e é caracterizado por um grande número de empréstimos lexicais do português, principalmente. Há outra variedade é o tétum terik, encontrado em zonas mais afastadas da capital timorense e com menos empréstimos lexicais, essa variedade menos falada.
} 
linguístico é muito recorrente nesse país - há contato de línguas asiáticas timorenses com línguas europeias (como o inglês e português) e contato com outras línguas asiáticas (como no caso das línguas chinesas trazidas pelos imigrantes). O foco dessa seção, no entanto, é olhar apenas para as línguas portuguesa e tétum no espaço linguístico social timorense. Visando ilustrar a situação da diversidade linguística descrita, apresenta-se o seguinte gráfico $^{18}$ :

Figura 5: Gráfico de línguas em Timor-Leste

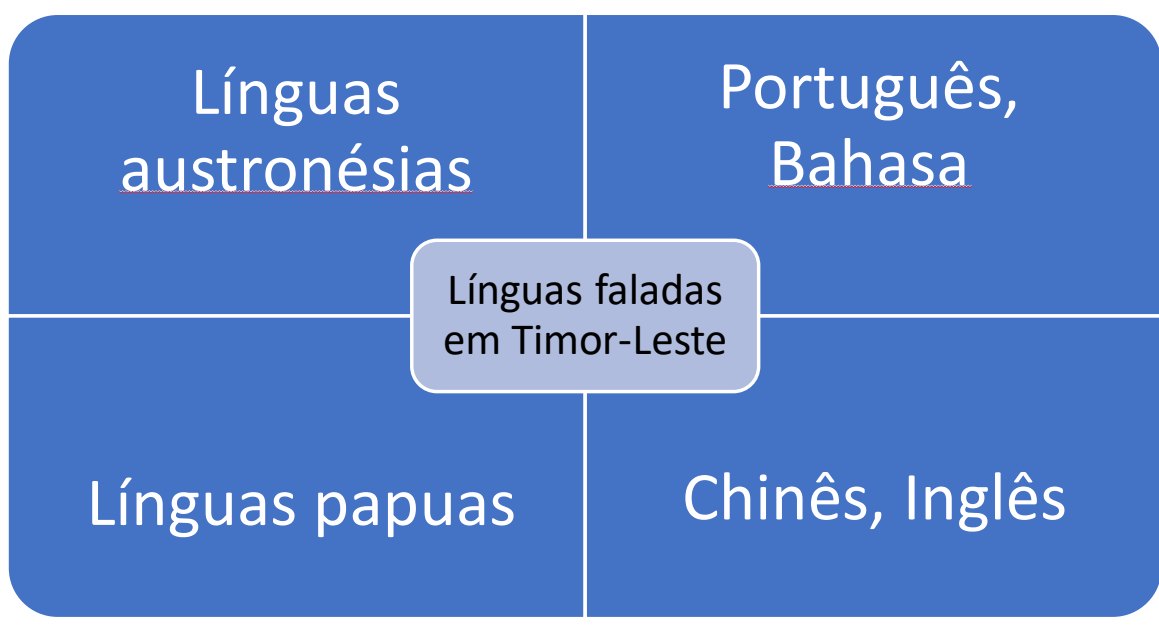

Fonte: Elaboração própria

Trazendo, primeiramente, a língua portuguesa como alvo da discussão, é importante comentar a continuidade do uso dessa língua depois dos 24 anos de interrupção causada pela presença militar indonésia. Em 2002, com a promulgação da constituição da república, Timor se reconecta com o passado português e faz da língua do colonizador, língua oficial para si próprio. Dessa maneira, Timor-Leste passa a ser um país lusófono, apesar de a língua portuguesa ser muito pouco falada pelos timorenses.

O tétum, por outro lado, é a língua mais falada do país. De origem austronésia, o tétum tem tido o 'status' de língua franca por mais de 400 anos. Macedo (2019) a respeito da língua em questão afirma: "os timorenses, quando não têm o tétum como L1, aprendem uma língua timorense conforme o distrito onde nascem e/ou da família. Posteriormente, por razões

\footnotetext{
${ }^{18} \mathrm{O}$ gráfico proposto não sugere nenhum tipo de hierarquia entre as línguas; é apenas uma maneira de ilustrar os grupos de línguas faladas no país em questão.
} 
sociais e comunicativas, aprendem tétum, que pode ser de maneira informal ou formal, se forem à escola (p. 13).

Foi mostrado que através da língua falada (e a variedade dessa língua), o sujeito assinala sua identidade como participante dessa sociedade. No caso plurilíngue de Timor, os falantes optam por uma ou outra língua ${ }^{19}$ a depender da situação social que estão no momento da interação - em casa falam uma língua timorense, em ambientes públicos podem usar o bahasa indonésio, em ambiente escolar/acadêmico ou órgão de administração pública, o português (SEVERO, 2010).

Como isso se dá com o caso da língua portuguesa, já que a grande maioria dos timorenses não falam efetivamente o português? Em 1975, antes da invasão indonésia, cerca de $5 \%$ da população era capaz de falar português - grande parte dessa porcentagem consistia do clero e funcionários do governo (RUAK, 2001). Como essa língua se comporta e é notada pelos agentes sociais? $\mathrm{O}$ caso de Timor com o português é realmente intrigante e tem chamado a atenção de linguistas, especialmente brasileiros e portugueses. Ruak (2001), ao abordar a importância do português em Timor-Leste, afirma:

Três factores chaves estiveram na base da manutenção da língua portuguesa: primeiro, a presença de intelectuais falantes da língua; segundo, a existência de um número elevado de timorenses conhecedores da língua escrita; terceiro, por ser a única ortograficamente mais desenvolvida na ilha. (...) Porém, como vimos atrás, apesar de já ser tão pobre a herança lusófona deixada pelos últi- mos governantes portugueses, acontecimentos posteriores ainda vieram deteriorá-la muito mais ao ponto de a eliminar por completo. (RUAK, 2001, p. 48)

Outro dado importante é o fato de o português ser considerado língua de resistência durante os anos de opressão causados pela Indonésia. O movimento de resistência timorense fazia uso do português, entre outras línguas. Falar português não apenas protegia as informações trocadas entre os membros da resistência, uma vez que os indonésios não entendiam o português, como reforçava a identidade do Movimento.

Nos tempos da guerra de posição, de 1975 à 1979, a língua oficialmente utilizada pela Resistência era o português, falado e escrito em qualquer

\footnotetext{
${ }^{19}$ É importante assinalar o fato de as línguas timorenses estarem espalhadas por todo o país. Cada distrito (TimorLeste é dividido politicamente em distritos) tem sua(s) própria(s) língua(s). O bi-plurilinguismo na nação referida é muito comum
} 
tipo de comunicação, desde o topo até a base. Embora lutássemos com dificuldades de toda a ordem, utilizávamos todos os recursos disponíveis para não só preservar a língua, mas, essencialmente, expandi-la aos menores e analfabetos, através de aprendizagem, até utilizando para isso carvão e casca de certas plantas para servir de papel. (RUAK, 2001, p. 47)

Uma pesquisa foi realizada com 35 participantes timorenses (19 homens e 16 mulheres) no primeiro semestre de 2019 através do Laboratório de Pesquisas em Contato Linguístico (LABPEC) da Universidade Federal Fluminense. Eles receberam um breve questionário via 'Google Forms' e, assim, participaram do estudo. O objetivo das perguntas elaboradas era conhecer pouco da relação entre línguas, pertencimento e identidade timorense. Os resultados ajudaram a entender o papel da língua portuguesa (e também do tétum) em Timor-Leste. Foram usadas 5 perguntas nesse questionário: i) Quantas línguas você fala? ii) Qual a língua que melhor representa você? iii) Qual a língua que melhor representa Timor Leste? iv) Se tétum não for sua língua materna, responda. De 1 a 10, que nota você daria para sua habilidade de falar e entender tétum? v) Na sua opinião, que língua todo timorense deve falar?

Os resultados obtidos revelaram que nenhum dos informantes afirmou ser monolíngue, na verdade, $35 \%$ deles afirmaram falar 5 línguas. No tocante à representatividade linguística, $80 \%$ deles disseram que o tétum é a língua que melhor os representa e somente $8 \%$ mencionaram o português em tal posição. Ao perguntar qual a língua representava melhor o Timor, a maioria deles concordou com o tétum (68\%), mas uma parte se mostrou favorável ao português nessa classificação (23\%). Mais uma vez, a maioria dos participantes pensa que o tétum é a língua que todo timorense deve falar (54\%); um outro grupo tem uma postura similar, $27 \%$ responderam que tétum e português são as línguas que todo timorense deve falar.

Uma breve análise desses resultados, baseado na discussão sobre espaço social feita anteriormente, mostra que o uso da língua portuguesa parece ser muito bem aceita e valorizada entre os agentes sociais timorenses, embora não seja língua materna deles. Temse pistas que o português é língua de prestígio social naquela nação; provavelmente pelo fato de ser oficial e língua de administração e outras razões político-sociais, como ter sido língua de resistência na recente passagem histórica de invasão indonésia. 


\section{O ESPAÇO LINGUÍSTICO POLÍTICO EM TIMOR-LESTE}

Já apresentado anteriormente, Timor-Leste é uma nação que lida com o fato de ter eleito uma língua oficial que não é língua materna de seus habitantes. Além disso, o percentual de timorenses que falam português é muito baixo. Existem muitos desafios que o país precisa enfrentar para efetivamente 'lusitanizar' linguisticamente os timorenses.

Lagares (2018) chama a atenção para o fato de a escolha de línguas oficiais não estar relacionada apenas com comunicação entre os falantes, mas com política. Ele mostra também que ao oficializar uma língua, o Estado considera-a "adequada para ser usada em todas as atividades políticas e administrativas de um país" (p. 62). Lembrando Bagno (2008), a relação entre línguas e políticas é bastante acentuada. Lagares (2018) recorda a escolha da língua hebraica para ser usada no Estado de Israel que atendeu razões religiosas e ideológicas e não puramente linguísticas. Até então o hebraico já não era falado e cerca de 10 milhões de judeus usavam o iídiche, uma língua de ampla tradição literária e com base germânica. O esforço político do Estado hoje colhe frutos: o hebraico é falado por cerca de 6 milhões de judeus e pelo menos 2 milhões de árabes em Israel.

É muito claro que a eleição do português como uma das línguas oficiais de Timor-Leste se deu por motivos políticos, assim como no caso israelense. O português já tinha um status de língua de resistência usado pelos membros do CNRT - Conselho Nacional de Resistência Timorense - e uma importância para os líderes de partidos políticos que votaram a favor do português. O discurso contrário à escolha do português baseava-se nas seguintes razões: i) o português é falado por $5 \%$ da população e esses pouco ainda não o falam fluentemente; ii) escolher o português é uma atitude nostálgica da velha geração aos tempos de colônia; iii) escolher o português é uma atitude autoritária e uma imposição linguística à população; iv) a nova geração usa o bahasa indonésio, o português é uma língua que eles não compreendem; v) o português é defendido pelos descendentes de portugueses que, de alguma forma, desejam reaver supremacia social; vi) a CPLP tem países distantes do Timor e não são potências econômicas (BRITO; CORTE-REAL, 2006).

Reportando um caso semelhante, Guiné-Bissau, nação africana com aproximadamente 1.417.000 habitantes, tem o português como língua oficial. Em Guiné, o português é língua de ensino e de comunicação em fóruns internacionais. Semelhante ao caso timorense, esta língua 
europeia é L1 de uma percentagem muito baixa e, certamente, não é a língua nacional. O que se destaca nesse país é o crioulo guineense, a língua franca, que estabelece ponte entre diferentes as comunidades. Somente cerca de $13 \%$ dos guineenses usam o português como segunda (ou terceira ou quarta) língua (EMBALÓ, 2008).

Ao lado do português, o tétum também foi escolhido como língua oficial em TimorLeste, como mostrado. Esta língua já era franca e nacional, amplamente falada no território timorense, era esperado que foi escolhida como oficial. Tétum e português sempre foram línguas parceiras durante os 500 anos de colonização portuguesa:

O tétum continua hoje e para o futuro necessitando desta parceria (com o português) para a sua constante caracterização e para o seu papel diferenciador, e Timor-Leste afirma-se como o único país soberano em todo o hemisfério oriental a tecer uma cultura austro-melanésica com ingredientes de sabor latino-luso-cristão. Assiste-se, portanto, a uma naturalidade na escolha do português, pela parceria secular com o tétum - que lhe valeu a elevação estatutária - que resulta numa interpenetração mutua entre as duas línguas, em que se tipifica o português falado por timorenses e em que o tétum absorve do português influências nos níveis fonológico, morfológico, sintático-semântico e pragmático. Se tentássemos eliminar todos os termos de origem portuguesa numa conversa dentro do contexto dos preparativos para a realização de uma actividade sociocultural - por exemplo, o casamento católico timorense diríamos que os noivos não chegariam a casar-se, pois, o casamento tornar-se-ia inviável. É por causa da cultura, da história, da política que se optou pela parceria estratégica do tétum-português para o estatuto oficial no país. (CORTE-REAL; BRITO, 2006, p. 129 - grifo nosso).

No aspecto educacional, tétum e português são as línguas de instrução usadas nas escolas. No que se refere ao português, atingir um número de professores capacitados é um desafio que nação precisar lidar. Muito embora o português esteja longe de ser uma língua falada amplamente na ilha timorense, sua presença é notada de modo claro na paisagem linguística. Como mostrado no trecho acima, o número de empréstimos lexicais portugueses no tétum é muito grande. A religião católica, muito enraizada na cultura local, é bastante respeitada mantendo o vínculo com a cultura portuguesa. Outro indício da aceitação da língua e cultura portuguesa é o uso de nomes nessa língua: $70 \%$ dos sobrenomes e mais de $90 \%$ dos nomes são portugueses. A isso pode-se acrescentar o fato de o hino nacional timorense ser em português somente, não em nenhuma das outras línguas locais.

Parece que a escolha política pelo regresso da língua portuguesa em Timor-Leste se traduz como um elemento de recuperação da identidade cultura, política e histórica desse 
povo, especialmente após aos 24 anos de abusos sofridos pelos indonésios. Hoje o português é língua política, de instrução e de aparente grande aceitabilidade social.

\section{CONSIDERAÇÕES FINAIS}

Neste texto, apresentamos um estudo panorâmico sobre a relação entre língua e espaço. Para compreender essa ligação, optou-se por dissertar sobre o espaço por meio de três perspectivas: geográfica, social e política. No espaço linguístico geográfico, foi apresentada a dialetologia tradicional e seus primeiros passos em traduzir os resultados de pesquisas linguísticas em mapas e atlas. Além disso, o texto mostrou que, apesar do aparente abandono que muitos pesquisadores deram ao conceito geográfico de espaço nos anos 1960, com o advento da sociolinguística laboviana, a conexão geografia e linguística resistiu às décadas e continua em andamento (CARDOSO, 2010). No tocante ao espaço social, recorreuse aos conceitos de Bourdieu a fim de compreender o papel dos falantes e suas línguas no espaço. Ao abordar o espaço linguístico político, mostrou-se a conexão entre fronteiras políticas e as línguas de uma região; o conceito europeu de Estado-nação e suas consequências na vida linguística de um país.

Timor-Leste em suas línguas e relação com o espaço foi brevemente apresentado com o intuito de exemplificar alguns conceitos trazidos com as discussões levantadas. Foi mostrado que pesquisas em dialetologia foram realizadas no país e que há linguistas (não timorenses) investigando o tema. Foi mostrado também que as diversas línguas timorenses muitas vezes são usadas no mesmo espaço social e ainda têm contato com o português. Levantou-se a hipótese de o português ser uma língua de prestígio e influência entre os timorenses. Em relação ao espaço linguístico político, foi exposto o fato de a constituição mencionar o tétum e o português como línguas oficiais.

Considera-se relevante e atual trazer o debate entre língua e espaço num momento em que o mundo, cada vez mais, se encontra em profundas mudanças e acreditamos que todo contato sociolinguístico está em constante movimento. Tudo isso é muito pertinente partindo do pressuposto que todo processo de interligação política, cultural, econômico é capaz de mudar a maneira como se entende elementos da vida em sociedade e, por conseguinte sua forma de se expressar, sua língua/linguagem. 


\section{REFERÊNCIAS}

ALBUQUERQUE, D. As línguas de Timor-Leste: perspectivas e prospectivas. In: Língua e Literatura. São Paulo, n 27, 2010, p. 313-335.

BARBIERS, S., Language and space: Structuralist and generative. In: PETER, A; SCHMIDT, J. E. (org.) Language and Space - An International Handbook of Linguistic Variation. Berlim/Nova lorque: Walter de Gruyter, 2010, p. 125-141.

BAGNO, M. Preconceito Linguístico: o que é, como se faz? 48. ed. São Paulo: Loyola edições. 2007.

BOURDIEU, P. A economia das trocas linguísticas: o que falar quer dizer. 2. ed. Tradução de Sérgio Miceli et al. São Paulo: Editora da UNESP. 2008.

CALVET, L. J. Sociolinguística: uma introdução crítica. Tradução de Marcos Marcionílio. São Paulo: Parábola Editorial, 2002.

CARDOSO, S. A. Geolinguística: tradição e modernidade. 1. Ed. São Paulo: Parábola editorial, 2010.

CARIOCA, Cláudia R. As funções sociais da língua e as políticas de difusão do Português no Timor-Leste. Delta, São Paulo, v. 32, p 421-447, 2016.

CORTE-REAL, B. A; BRITO, R. H. P. Aspectos da Política Linguística de Timor-Leste, desvendando contracorrentes. In: BASTOS, Neusa Barbosa (Org.). Língua Portuguesa: reflexões lusófonas. São Paulo: EDUC, 2006.

CRYSTAL, D. Dictionary of Linguistics and Phonetics. 6 ed. Blackwell Publishing. 2008.

EMBALÓ, F. O crioulo da Guiné-Bissau: Língua nacional e fator de identidade nacional. Revista Brasileira de Estudos do Contato Linguístico. São Paulo, v. 18, p. 101-107, 2008.

GAL, S. Language and political spaces. In: PETER, A; SCHMIDT, J. E. (org.) Language and Space - An International Handbook of Linguistic Variation. Berlim/Nova lorque: Walter de Gruyter, 2010, p. 33-49.

HIGGINS, C. Space, place and language. In S. Canagarajah (Org) The Routledge Handbook of Migration and Language. New York: Routledge, 2017.

JOHNSTONE, B. Language and geographical space. In: PETER, A; SCHMIDT, J. E. (org.) Language and Space - An International Handbook of Linguistic Variation. Berlim/Nova lorque: Walter de Gruyter, 2010, p. 1-17.

LAGARES, X. C. Qual política linguística? 1. ed. São Paulo: Parábola. 2018. 
MACEDO. A. L. S. A modificação de grau em tétum: uma proposta em semântica escalar. 2019. 108 f. Dissertação. (Mestrado em Estudos da Linguagem) Universidade Federal Fluminense, Niterói.

MAEHLUM, B. Language and social spaces. In: PETER, A; SCHMIDT, J. E. (org.) Language and Space - An International Handbook of Linguistic Variation. Berlim/Nova lorque: Walter de Gruyter, 2010, p. 18-32.

MOTA, J; CARDOSO, S. A. Dialectologia brasileira: O Atlas linguístico do Brasil. In: Revista ANPOLL, n. 8, p 41-57, jan/jun 2000.

RUAK, T. M. A Importância da língua portuguesa na resistência contra a ocupação indonésia. In: Camões - Revista de Letras e Culturas Lusófonas, Lisboa, n. 14, 2001.

SAVEDRA, M; PEREZ, G. Plurilinguismo: Práticas Linguísticas de imigrantes brasileiros no Suriname. In: Oragon: Revista do Instituto de Letras da UFRGS, v. 32 n. 62, 2017.

SAVEDRA, M; MAZELLI-RODRIGUES, L. Língua pomerana em percurso histórico brasileiro: uma variedade (neo)autóctone. In: Working Papers in Linguística. Florianópolis, v. 18 (1), jan./jul. 2017, 6-22.

SEVERO, C. G. Questões de língua, identidade e poder: hibridismos em Timor Leste. In: Revista Brasileira de Linguística Aplicada, Belo Horizonte, v. 11, 2011, p. 95-113.

WILLIAMS-VAN KLINKEN, C; WILLIAMS, R. Mapping the mother tongue in Timor-Leste Who spoke what where in 2010? Dili Institute of Technology, Dili, 2015

Recebido em 17 de julho de 2020.

Aprovado em 08 de novembro de 2020

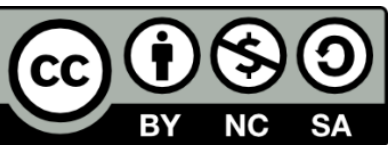

